\title{
A Creep Cavity Growth Model for Creep-Fatigue Life Prediction of a Unidirectional $\mathrm{W} / \mathrm{Cu}$ Composite
}

Yong-Suk Kim

Research Institute of Industrial Science and Technology

Pohang, Korea

and

Michael J. Verrilli and Gary R. Halford

Lewis Research Center

Cleveland, Ohio

Prepared for the

Second Symposium on Advances in Fatigue Lifetime Predictive Techniques sponsored by the American Society for Testing and Materials

Pittsburgh, Pennsylvania, May 4-5, 1992 


\title{
A CREEP CAVITY GROWTH MODEL FOR CREEP-FATIGUE LIFE PREDICTION OF A
}

\section{UNIDIRECTIONAL W/Cu COMPOSITE}

\author{
Yong-Suk Kim \\ Research Institute of Industrial Science and Technology \\ Metallic Materials Division \\ P.O. Box 135, Pohang 790600, Korea \\ Michael J. Verrilli and Gary R. Halford \\ National Aeronautics and Space Administration \\ Lewis Research Center \\ Cleveland, Ohio 44135
}

\section{SUMMARY}

A microstructural model has been developed to predict creep-fatigue life in a $[0]_{4}, 9$ vol. $\%$ tungsten fiber-reinforced copper matrix composite at the temperature of $833 \mathrm{~K}$. The mechanism of failure of the composite is assumed to be governed by the growth of quasi-equilibrium cavities in the copper matrix of the composite, based on the microscopically-observed failure mechanisms. The methodology uses a cavity growth model developed for prediction of creep fracture. Instantaneous values of strain rate and stress in the copper matrix during fatigue cycles were calculated and incorporated in the model to predict cyclic life. The stress in the copper matrix was determined by use of a simple two-bar model for the fiber and matrix during cyclic loading. The model successfully predicted the composite creep-fatigue life under tension-tension cyclic loading through the use of this instantaneous matrix stress level. Inclusion of additional mechanisms such as cavity nucleation, grain boundary sliding, and the effect of fibers on matrix-stress level would result in more generalized predictions of creep-fatigue life.

\section{INTRODUCTION}

Metal matrix composites are considered to be very promising materials for aerospace applications because of their higher use temperatures, stiffness, and strength-to-weight ratio than comparable monolithic metals (ref. 1). Due to the expected use of the composites in cyclic loading applications, characterization of their fatigue behavior is important. It is also crucial to have a reliable life prediction scheme for the material. Few high-temperature fatigue life prediction models are reported for composite materials.

Sound understanding of failure characteristics is essential to the development of a life prediction methodology. Fatigue failure of a metal matrix composite is not a simple process. Matrix cracking, fiber-matrix interfacial failure, and fiber cracking can be major elements of the failure process. These damage processes work together in some manner to result in composite failure. It will be difficult to formulate a life prediction methodology which models all these phenomena together. However, it may be possible to identify a dominant failure mechanism in a specific composite system under a particular condition. Modeling of a dominant failure mode will be much simpler and it can be utilized as the basis of a simple fatigue life prediction methodology. 
The purpose of this paper is to present a simple creep-fatigue life prediction model of a composite based on microscopically-observed failure processes. The material studied in this effort is a $[0]_{4}$, tungsten-fiber-reinforced, OFHC copper-matrix composite. Previous research on the cyclic failure of this composite at high temperatures has shown that the composite fails primarily due to degradation of the copper matrix ( refs. 2 and 3). Fatigue cracks were found to initiate and propagate in the copper matrix through cavity nucleation, growth, and eventual coalescence. The fibers neck and rupture locally after the surrounding matrix fails and then complete failure of the composite ensues. Since the dominant failure mode was cracking of the copper matrix, fatigue failure of the composite was assumed to occur when the matrix fails. Matrix dominated fatigue damage was utilized as a failure criterion of the composite in the model.

Fibers were considered to affect the stress level in the copper matrix during the fatigue loading, however their failure characteristics were not considered in the calculation of the fatigue lives. The analysis in this paper is limited to isothermal, tension cyclic loading. Interfacial debonding or degradation were not considered in the model, as it did not play a major role in these fatigue loading conditions (refs. 2 and 3).

\section{MATERIAL AND FATIGUE TEST PROCEDURES}

The tungsten-copper ( $\mathrm{W} / \mathrm{Cu}$ ) composite was composed of a matrix of OFHC copper and continuous fibers of tungsten 218 wires with a diameter of $200 \mu \mathrm{m}$. The 4 ply composite plates were manufactured through an arc-spraying technique and contained 9 vol\% $\%$ tungsten fibers. Rectangular cross section specimens were machined with all fibers aligned parallel to the loading direction.

Isothermal fatigue tests were performed using a $90 \mathrm{kN}$ servo-hydraulic test system. The test temperature was $833 \mathrm{~K}$ and the test environment was a vacuum of $5 \times 10^{-6}$ torr. Two cycle frequencies were employed, 0.05 and $0.5 \mathrm{~Hz}$. The waveform was triangular. All tests were performed in load control with an $R$ ratio of 0.07 ( $R=$ minimum load/maximum load). The test procedure is described in more detail in references 2 and 3.

Fatigue fracture surfaces and polished sections of failed specimens were examined using optical and scanning electron microscopy (SEM). SEM micrographs were also used to measure the cavity spacing. Only those cavities which lay perpendicular to the viewing direction were counted to determine the cavity spacing.

\section{THE FATIGUE FAILURE MODEL BY CREEP CAVITY GROWTH \\ Cavity Growth Model During Fatigue}

To model fatigue failure of the composite through intergranular cavity growth and coalescence processes in the matrix, the mechanisms of each step of the cavitation process-cavity nucleation and growth-should ideally be evaluated. Gittins (ref. 4) and Wang and Nix (ref. 5) have reported that, at high temperatures, the cavity nucleation process is very fast and the contribution of the cavity nucleation process to total life time during fatigue and creep is negligible. They claimed that it is reasonable to determine cyclic life by modeling only the cavity growth process at high temperature. There is other experimental evidence to support the idea of 
neglecting the cavity nucleation process in our composite material. Figure 1 is a scanning electron microscope (SEM) micrograph of the copper matrix in the as-received composite. Preexisting cavities can be seen as dark spots. Although not evident in this micrograph, they are along the grain boundaries. These cavities are believed to be the result of the composite fabrication process, with atomic argon collecting at the grain boundaries to form bubbles. Note their nonuniform size and spacing. These pre-existing cavities imply that bypassing the cavity nucleation process in the model is a reasonable assumption for this case. For simplicity, we assumed the initial cavity size and spacing were uniform.

Cavity growth mechanisms under cyclic loading conditions are not as well understood as those under monotonic creep conditions. Some researchers reported that cavity growth during fatigue is controlled solely by vacancy diffusion (refs. 4 and 6 to 8). However most of these studies treated cavity growth under low applied stress levels and concentrated on the initial transient cavity growth. These results do not seem to be general and fail to explain the cavity growth under high applied stresses and when growth is not transient. In light of this, the approach taken in the present modeling effort was to utilize a cavity growth relationship developed for creep loading. The use of a creep cavity growth law is not unrealistic since the cyclic loading conditions employed in the present study were at high temperatures and relatively low strain rates. Under such conditions creep-fatigue interaction would be likely to occur. Microscopic examination of the failed fatigue specimens (ref. 2) suggested that the creep process played a major role in the intergranular failure of the copper matrix through cavitation processes.

Under creep conditions, diffusion processes govern cavity growth when the initial cavities are small and closely spaced. On the other hand, when cavities are large and widely spaced, they do not grow through a diffusion process alone. Rather, their growth is through plastic flow of the surrounding matrix coupled with diffusional processes (refs. 9 to 12). This coupled cavity growth mechanism is used in the present analysis. Several workers have successfully used this coupled cavity growth mechanism to predict creep fracture in copper and copper alloys (refs. 5, 13 , and 14).

A number of models have been proposed to treat the case of grain boundary cavity growth through coupled creep plasticity and diffusion (refs. 9 to 12). Chen and Argon (ref. 11) characterized the interaction between diffusion and power-law creep by introducing a diffusion distance, $\Lambda$

$$
\Lambda=\left[\frac{\mathrm{D}_{\mathrm{B}} \delta_{\mathrm{B}} \Omega \sigma}{\mathrm{kT} \dot{\varepsilon}}\right]^{1 / 3}
$$

where $\Omega$ is the atomic volume, $\mathrm{D}_{\mathrm{B}} \delta_{\mathrm{B}}$ is the product of the grain boundary diffusivity and grain boundary thickness, $\mathrm{T}$ is the temperature, $\mathrm{k}$ is Boltzmann's constant, $\dot{\varepsilon}$ is the strain rate, and $\sigma$ is the applied normal stress. Cavity growth is assumed to occur by grain boundary diffusion near a cavity tip within the diffusion distance and by power-law creep midway between the cavities. The diffusion distance is dependent on the applied stress and the strain rate. Martinez and Nix (ref. 12) extended this coupled cavity growth law of Chen and Argon to include capillarity effects. Their cavity growth rate, $\dot{a}$, is given by 


$$
\begin{gathered}
\dot{\mathrm{a}}=\frac{\mathrm{a} \dot{\varepsilon}}{2 \mathrm{~h}(\varphi)}\left(\frac{\Lambda}{\mathrm{a}}\right)^{3} \mathrm{Q}(\xi) . \\
{\left[1-\frac{2 \mathrm{a}}{(\mathrm{a}+\Lambda)^{2}} \frac{\gamma_{\mathrm{S}}}{\sigma}-2 \sin (\varphi) \frac{\gamma_{\mathrm{S}}}{\sigma \mathrm{a}}\left(1-\xi^{2}\right)\right]}
\end{gathered}
$$

where $\mathrm{a}$ is the cavity radius, $\xi=\mathrm{a} /(\mathrm{a}+\Lambda), \varphi$ is the tip angle of the cavity defined as $\cos ^{-1}=\left[\gamma_{\mathrm{B}} / 2 \gamma_{\mathrm{S}}\right], \gamma_{\mathrm{B}}$ and $\gamma_{\mathrm{S}}$ are energies of the grain boundary and surface, respectively. $\mathrm{h}(\varphi)$ is a geometrical factor given by

$$
h(\varphi)=\frac{1}{\sin (\varphi)} \cdot\left[\frac{1}{1+\cos (\varphi)}-\frac{\cos (\varphi)}{2}\right]
$$

and the function $Q(\xi)$ is defined by

$$
\mathrm{Q}(\xi)=\left[-\ln (\xi)-\frac{1}{4} \cdot\left(3-\xi^{2}\right)\left(1-\xi^{2}\right)\right]^{-1}
$$

The material and microstructural constants used for an evaluation of the above cavity growth model are shown in table I. As indicated by equation (2), the instantaneous values of the strain rate and the stress in the copper matrix during the fatigue cycle must be determined to calculate the cavity growth rate.

\section{Deformation Mode of the Copper Matrix During Fatigue}

During the high temperature cyclic loading employed in this study, the copper matrix experiences both time-independent and time-dependent deformation. The time-independent deformation is composed of elastic and plastic component. Hooke's law is used to characterize the elastic deformation. For power-law hardening plasticity, the time-independent plastic strain can be described by

$$
\varepsilon_{\mathrm{pl}}=\mathrm{D} \sigma^{1 / \mathrm{N}}
$$


where $\mathrm{l} / \mathrm{N}$ is a hardening exponent and the coefficient $\mathrm{D}$ relates stress and time-independent plastic strain. The time-independent plastic strain rate can be determined through differentiation of equation (5). The total time-independent strain rate is given by:

$$
\dot{\varepsilon}_{\text {time independent }}=\frac{1}{\mathrm{E}} \dot{\sigma}+\frac{\mathrm{D}}{\mathrm{N}} \sigma^{(1 / \mathrm{N})-1} \dot{\sigma}
$$

The values of constants $\mathrm{D}$ and $\mathrm{N}$ are given in table $\mathrm{I}$. The time-dependent deformation of the copper matrix was assumed to be power law creep as given in the following equation:

$$
\dot{\varepsilon}_{\text {creep }}=\mathrm{A} \frac{\mu|\mathrm{b}|}{\mathrm{kT}} \mathrm{D}_{\mathrm{L}}\left(\frac{\sigma}{\mu}\right)^{\mathrm{n}}
$$

where $\mathbf{A}$ is the creep constant, $\mu$ is the shear modulus, $\mathbf{b}$ is the Burger's vector, $\mathrm{D}_{\mathrm{L}}$ is the lattice diffusivity, $\mathrm{n}$ is the stress exponent for steady state creep, and $\sigma$ is the applied stress.

For an isothermal test condition, this equation simplifies to

$$
\dot{\varepsilon}_{\text {creep }}=\mathrm{B} \sigma^{\mathrm{n}}
$$

with the constant $\mathrm{B}=9.1 \times 10^{-43} \mathrm{~Pa}^{-\mathrm{n}} \sec ^{-1}, \mathrm{n}=5$ for pure copper at $833 \mathrm{~K}$. The total strain rate is the sum of all three components (elastic, plastic, and creep) and is given by:

$$
\dot{\varepsilon}_{\text {total }}=\frac{1}{\mathrm{E}} \dot{\sigma}+\frac{\mathrm{D}}{\mathrm{N}} \sigma^{(1 / \mathrm{N})-1} \dot{\sigma}+\mathrm{B} \sigma^{\mathrm{n}}
$$

During the tensile loading portion of the fatigue cycle, the contribution from the timeindependent plasticity increases as the stress increases. On the other hand, during the unloading portion of the cycle, the time-independent plasticity is neglected by setting $\mathrm{D}=0$ so that only the elastic strain and creep strain terms operate. Similarly, compressive stresses are assumed to have no influence on cavity growth.

Note that residual stresses which result from the composite manufacturing process have been ignored. The copper matrix has very low strength and creep resistance at the test temperature of $833 \mathrm{~K}$ and these residual stresses would likely be relieved. Thus, it is reasonable to assume zero axial residual stress in the matrix.

The average stress level in the copper matrix was calculated by applying an assumption of an isostrain condition to both constituents of the composite. Assuming isostrain conditions for the two constituents means that the fibers and the matrix deform with the same amount of axial strain $\left(\varepsilon_{11}\right)$ in the direction of the applied stress. For our continuous-fiber-reinforced composite 
material loaded in tension-tension fatigue, this assumption is reasonable. However it is important to be aware of the fact that the in-situ copper matrix deformation can be different from that of monolithic copper because of potential interaction between the matrix and reinforcing fibers. In the present study, we have ignored any effect of the stress fields around adjacent fibers on the average matrix stress state. This is a reasonable assumption for this low strength matrix and low fiber volume fraction composite.

The following procedure was used to calculate the axial stress in the copper matrix. Cyclic stress-strain curves for the composite were measured during the fatigue experiments. As stated above, the axial strain in the matrix was assumed to be equal to the axial strain in the composite. Knowing the stress-strain behavior of copper at the composite test temperature, the stress in the copper matrix corresponding to the strain of interest was then calculated. This calculated stress was used in the model for the cavity growth.

\section{Cavity Size Calculation}

Fatigue failure was modeled using the cavity growth law (eq. (2)) and deformation mode (eq. (9)) as described in the preceding sections. As explained earlier, all the cavities in the copper matrix are assumed to pre-exist. Upon loading they grow simultaneously at the same rate. All cavities are considered to behave equally under the given loading conditions and therefore one cavity can represent all the other cavities. In the model, growth of one cavity is simulated and failure cycles of the composite is calculated based on this growth. The failure of the composite occurs when the cavity in the matrix reaches a critical size. The radius, a, of the cavity can be related to the damage parameter, $\omega$. The damage parameter, $\omega$, is the area fraction of the cavities, defined as $\mathrm{a}^{2} / \mathrm{c}^{2}$, where $\mathrm{c}$ is half the spacing between the cavities. In the model, when $\omega$ reached a critical value, the specimen was assumed to fail. Observations of fracture surfaces of the copper matrix show that fracture occurs when cavities link together. Yet some plastic tearing of ligaments between cavities has also been observed. Based on microscopic examinations of fracture surfaces of failed composite specimens a value of 0.8 was used as the composite failure criteria.

Fatigue failure was simulated through numerical calculation of the size of a cavity in the copper matrix. The cavity size, a, at an arbitrary time, $t$, during the fatigue cycling is given by

$$
\mathrm{a}=\mathrm{a}_{0}+\int_{\mathrm{t}_{0}}^{\mathrm{t}} \dot{\mathrm{a}} \mathrm{dt}
$$

where $a_{0}$ is the cavity size at time $t_{0}$ and $\dot{a}$ is the cavity growth rate at time $t_{0}$ given by equation (2). The initial cavity size $a_{0}$ can be assumed to be equal to the critical nucleus size which is given by (ref. 5)

$$
\mathrm{a}_{0}=\frac{2 \gamma_{\mathrm{s}}}{\sigma}
$$


As will be shown, we did not use this relationship but we based $a_{0}$ on the size of pre-existing cavities in the as-received composite matrix.

\section{EXPERIMENTAL RESULTS AND MODEL PREDICTIONS}

The typical cyclic stress-strain response of the composite is given in figure 2. Each hysteresis loop shows significant inelastic deformation. The loop attains its stabilized shape after about five cycles and retains this shape until failure. The composite experiences a continual increase in the mean strain (ratchetting) as indicated by the translation of the loops along the strain axis.

Figure 3 is a plot of the peak cyclic strain as a function of cycle number. The strain ratchetting is again clearly visible in this plot. The curves have three distinct regions analogous to a typical creep curve for a monolithic material. An initial transient period, where the rate of increase of the maximum cyclic strain with cycle number increases gradually, is followed by a steady state region of constant slope. The third region is characterized by a rapid increase in the maximum strain as a function of cycle number, which concludes with specimen failure. No significant change of the elastic modulus was detected until the last few fatigue cycles.

Table II summarizes the fatigue test results. As shown in the table, a small change in the applied fatigue stress level results in a significant change in fatigue life. This sensitivity is apparent in figure 4, where the plot of applied stress range versus fatigue life shows a shallow slope.

Figure 5 depicts a secondary crack of a polished longitudinal section of a failed specimen. The crack propagation process in this composite under the cyclic loading is clearly indicated here. Cracks initiated and propagated in the copper matrix and the fibers necked down and failed following the failure of the surrounding matrix. This sequence of events was confirmed by examining interrupted test specimens. An examination of the fracture surface (fig. 6) clearly shows the intergranular nature of the matrix cracking. More details concerning the failure characteristics can be found in reference 2 .

Cavity growth predicted by the model (eq. (10)) is shown in figure 7 as a plot of the cavity radius versus time. As seen in this figure, the initial cavity growth is characterized by a gradual increase in the cavity radius. The rate of cavity growth, which is the slope of the curve, increases gradually with time. A region of near steady state cavity growth then follows. The final stage of the cavity growth is very rapid and failure occurs as the cavity radius approaches the critical radius. The cavity growth curve shows similarity to the composite maximum strain response as a function of cycles, as shown in figure 3. This similarity suggests that the composite failure is dependent on the matrix failure as described by the cavity growth model.

A comparison of the predicted and measured fatigue lives are summarized in table III. Three different initial cavity sizes were used in calculation of the model predictions. The predictions shown in table III were generated assuming an initial cavity size of $0.40 \mu \mathrm{m}$. The numerically predicted results agree fairly well with the experimental results.

To assess the predictive capability of the model under different fatigue conditions, the model was used to predict fatigue lives of tests performed under different cycle frequency, i.e., $0.5 \mathrm{~Hz}$. Table IV compares the experimental and predicted results. Again the model predictions 
agreed fairly well with the experimental results. Figure 8 compares the model predictions with the experimental results for both test frequencies, showing the good agreement for all tests.

\section{DISCUSSION}

Analysis of fatigue failure of a composite is complex due to the presence of the reinforcing fibers. As stated earlier, typically more than one failure mechanism can be identified for composites experiencing fatigue loads. However one failure mechanism often is dominant. Matrix dominated fatigue failure of a continuous-fiber-reinforced composite likely occurs if the matrix material has a lower fatigue endurance than the reinforcing fiber (ref. 15). Matrix dominated failure of 9 vol. $\%$ tungsten fiber reinforced copper at elevated temperature would be expected due to the known high temperature mechanical behavior of copper and the relatively low volume fraction of the reinforcing fiber. The ductility of copper decreases with increasing temperature because of an enhancement of cavitation along grain boundaries (ref. 16).

Intergranular cavitation is a typical form of creep-fatigue damage. For the hightemperature fatigue in the present study, r-type grain boundary cavitation due to stresses acting normal to grain boundaries was found to be a major failure mechanism. However other failure mechanisms such as transgranular cracking or wedge type cracking can also occur. Although these processes can influence the fatigue life, only r-type grain boundary cavitation was used for the present modeling. The fact that the predictions were in good agreement with the experimental data suggests that mechanisms other than r-type grain boundary cavitation are secondary failure mechanisms for the fatigue loading considered here.

It was assumed that evenly-spaced cavities of a critical size were nucleated upon initial load application. The contribution of continued additional cavity nucleation was not taken into account in the calculation of fatigue lives. To extend this model to more general cyclic loading conditions (i.e., cycles which include applied compressive loads, or to low or very high temperatures), the model should include a term to treat cavity nucleation. Some researchers have studied the effect of grain boundary sliding on cavity nucleation and growth (refs. 17 to 19). Grain boundary sliding induces a high stress concentration near particles located along grain boundaries or grain boundary triple junction points. The high stress concentration can affect the cavity nucleation and result in intergranular failures of a different nature, similar to wedge-type cracking. The effect of grain boundary sliding would be more pronounced at higher applied stresses with compression. Hence a treatment of both cavity nucleation and growth could make the model useful for a wider range of fatigue conditions.

We assumed that compressive stresses had no influence on cavity growth. However, matrix stresses are probably completely reversed. Verrilli et al. (ref. 20) studied the effect of varying the mean stress during cyclic loading on the rate of grain boundary cavitation for copper at $678 \mathrm{~K}$. They found that even under cyclic compression loading $\left(\mathrm{R}_{\sigma}=-\infty\right)$ cavity volume fraction increased with continued fatiguing. Thus, the cavity growth law incorporated in this model should be modified to treat cycles with compressive stresses and various mean stresses.

As stated earlier, several different initial cavity sizes were used in calculation of the predictions. Under the same loading conditions the model predicted that cavities with initial cavity size smaller than a critical size shrank and sintered due to the surface tension effects. This is believed to be caused by capillarity effects, which occur as the applied stress decreases, on cavities which are smaller than a critical size. Some researchers have reported the possibility of 
cavities larger than the critical size undergoing a process of rounding and minimum growth in the early stages of growth (ref. 9). Cavity shrinkage predicted by the model confirms a similar observation in other work (ref. 8). As stated above, a more generalized treatment would include a term to account for nucleation of cavities above this critical size. Except for the cases in which healing of cavities occurred in the early stage of cycling, little difference in the modelpredicted lives as a function of initial cavity size was evident.

The analysis used to determine the stress in the copper matrix could be improved. The present model did not account for all of the influence of the reinforcing fiber on the matrix stress. This influence could be important for high volume fractions. For instance, during deformation when the fiber deforms elastically and the matrix plastically, the influence of the mismatch of the Poisson's ratio between the fiber and the matrix could be significant. Hence a more sophisticated treatment of the influence of fibers on matrix stress would improve the stress analysis of the matrix and therefore the applicability of the model to composites having various volume fractions of fibers.

One difficulty encountered during the computation was a determination of the strain in the matrix from the composite stress-strain curve and knowledge of the copper stress-strain curve. A better composite stress analysis scheme could allow one to independently trace the stressstrain behavior of the two constituents, thus making the calculations employed in this study simple.

\section{SUMMARY OF RESULTS}

1. A fatigue life prediction model for unidirectional metal matrix composites was developed which describes fatigue damage through the growth of grain boundary cavities in the matrix of a unidirectional tungsten fiber-reinforced copper matrix composite. This methodology, based on microscopically-observed failure mechanisms, successfully predicted experimentally-measured fatigue lives of the unidirectional composites tested using a zero-tension load control test technique.

2. The methodology uses a model originally developed for prediction of creep fracture. It is based on quasi-equilibrium cavity growth controlled by coupled diffusion and plasticity. Instantaneous values of strain rate and stress during the fatigue cycles were determined in order to predict the fatigue life.

3. Other possible fatigue damage mechanisms such as cavity nucleation, grain boundary sliding, and the influence of reinforcing fibers on the stresses in the matrix should be incorporated into the model for more general application.

\section{ACKNOWLEDGMENT}

This work was done while the first author held a National Research Council - NASA Lewis Research Center Research Associateship. Special thanks are given to Dr. T.P. Gabb for his careful SEM analysis. 


\section{REFERENCES}

1. Chou, T.-W.; McCullough, R.L.; and Pipers, R.B.: Composites. Sci. Amer., vol. 255, no. 4, 1986, pp. 192-201.

2. Kim, Y.-S.; Verrilli, M.J., and Gabb, T.P.: Characterization of Failure Processes in Tungsten Copper Composites Under Fatigue Loading Conditions. NASA TM-102371, 1989.

3. Verrilli, M.J.; Kim, Y.-S.; and Gabb, T.P.: High Temperature Fatigue Behavior of Tungsten Copper Composites. Fundamental Relations Between Microstructures and Mechanical Properties of Metal Matrix Composites; Proceedings of the Symposium, M.N. Gungan and P.K. Liau, eds., TMS, Warrendale, PA, 1990, pp. 479-496.

4. Gittins, A.: Mechanisms of Cavity Growth in Copper During High-Temperature Fatigue. Met. Sci. J., vol. 2, Mar. 1968, pp. 51-58.

5. Wang, J.S.; and Nix, W.D.: A Numerical Model for Prediction of Creep Fracture. Mater. Sci. Eng., vol. 89, May 1987, pp. 73-80.

6. Skelton, R.P.: Growth of Grain Boundary Cavities During High Temperature Fatigue. Philos. Mag., vol. 14, 1966, pp. 563-572.

7. Weertman, J.R.: Fatigue Induced Cavitation in Single-Phase Material. Can. Metall. Q., vol. 18 , no. 1,1979 , pp. 73-81.

8. Tang, N.Y.; and Plumtree, A.: A Note on Grain-Boundary Diffusion Controlled Cavity Growth During Elevated Temperature Fatigue. Metall. Trans., vol. 16A, no. 2, 1985, pp. 300-302.

9. Beere, W.; and Speight, M.V.: Creep Cavitation by Vacancy Diffusion in Plastically Deforming Solid. Met. Sci., vol. 12, no. 4, 1978, pp. 172-176.

10. Edward, G.H.; and Ashby, M.F.: Intergranular Fracture During Power-Law Creep. Acta Metall., vol. 27, no. 9, 1979, pp. 1505-1518.

11. Chen, I.-W.; and Argon, A.S.: Diffusible Growth of Grain-Boundary Cavities. Acta Metall., vol. 29, no. 10, 1981, pp. 1759-1768.

12. Martinez, L.; and Nix, W.D.: Effects of Capillarity on Intergranular Cavity Growth Controlled by Diffusion and Plasticity. Scripta Metall., vol. 15, no. 7, 1981, pp. 757-761.

13. Wang, J.S.; Martinez, L.; and Nix, W.D.: A Study of Intergranular Cavity Growth Controlled by the Coupling of Diffusion and Power Law Creep. Acta Metall., vol. 31, no. 6,1983 , pp. 873-881.

14. Kim, Y.-S.; and Nix, W.D.: Numerical Analysis of Creep Crack Growth in Precavitated Polycrystalline Copper. Mater. Sci. Eng., vol. A127, 1990, pp. 41-50. 
15. Johnson, W.S.: Fatigue Testing and Damage Development in Continuous Fiber Reinforced Metal Matrix Composites. NASA TM-100628, 1988.

16. Nieh, T.G.; and Nix, W.D.: The Information of Water Vapor Bubbles in Copper and Their Effect on Intergranular Creep Fracture. Acta Metall., vol. 28, no. 5, 1980, pp. 557-566.

17. Raj, R.; and Ashby, M.F.: On Grain Boundary Sliding and Differsional Creep. Metall., Trans., vol. 2, no. 4, 1971, pp. 1113-1127.

18. Raj, R.; and Ashby, M.F.: Grain Boundary Sliding and the Effects of Particles on its Rate. Metall., Trans., vol. 3, no. 7, 1972, pp. 1937-1942.

19. Wingrove, A.L.; and Taplin, D.M.R.: A Note on Grain Boundary Sliding and Cavitation is Iron. Scripta Metall., vol. 3, no. 9, 1969, pp. 649-654.

20. Verrilli, M.; Weertman, J.R.; and Spooner, S.: Influence of Void Nucleation on Growth Rates on High Temperature Fatigue. Basic Questions in Fatigue, vol. II, ASTM STP-924, R.P. Wei and R.P. Gangloff, eds., ASTM Philadelphia, PA, 1988, pp. 89-100. 
TABLE I.-MATERIAL AND MICROSTRUCTURAL CONSTANTS

FOR COPPER

\begin{tabular}{|ll|}
\hline A & creep constant, $5.54 \times 10^{6}$ \\
a & the distance from the center to the tip of the cavity or the cavity radius \\
c & the cavity half spacing, the cavity half spacing is $1 \mu \mathrm{m}$ \\
$\mathrm{D}$ & strain hardening coefficient at $833 \mathrm{~K}, 4.56 \times 10^{-33} \mathrm{~Pa}^{\mathrm{N}}$ \\
$\mathrm{D}_{\mathrm{B}} \delta_{\mathrm{B}}$ & the product of boundary diffusion and boundary thickness \\
$\mathrm{D}_{\mathrm{B} 0} \delta_{\mathrm{B}}$ & the pre-exponential for boundary diffusion, $5.12 \times 10^{-15} \mathrm{~m}^{3} / \mathrm{sec}$ \\
$\mathrm{D}_{\mathrm{L} 0}$ & the pre-exponential for lattice diffusion, $2 \times 10^{-5} \mathrm{~m}^{2} / \mathrm{sec}$ \\
$\mathrm{Q}_{\mathrm{B}}$ & the activation energy for grain boundary diffusion, $1.04 \times 10^{5} \mathrm{~J} / \mathrm{mole}$ \\
$\mathrm{Q}_{\mathrm{L}}$ & the activation energy for lattice diffusion, $1.97 \times 10^{5} \mathrm{~J} / \mathrm{mole}$ \\
$1 / \mathrm{N}$ & strain hardening stress exponent for pure copper at $833 \mathrm{~K}, 4.225$ \\
$\mu$ & shear modulus, $4.2 \times 10^{10} \times\left[1-(\mathrm{T}-300) \times 3.97 \times 10^{-4}\right] \mathrm{Pa},[\mathrm{T}(\mathrm{K})]$ \\
$\gamma_{\mathrm{B}}$ & the grain boundary free energy, $0.67 \mathrm{~J} / \mathrm{m}^{2}$ \\
$\gamma_{\mathrm{S}}$ & the surface free energy, $1.99 \mathrm{~J} / \mathrm{m}^{2}$ \\
$\sigma$ & the applied normal stress $($ tension $)$ \\
$\Omega$ & the atomic volume, $1.18 \times 10^{-29} \mathrm{~m}^{3}$ \\
$\omega$ & the area fraction of cavities, $(\mathrm{a} / \mathrm{c})^{2}$ \\
\hline
\end{tabular}

TABLE II.-FATIGUE DATA FOR $[0]_{4}$,

9 Vol. \% W/Cu AT $833 \mathrm{~K}$ (CYCLE

FREQUENCY $=0.05 \mathrm{~Hz}$ )

\begin{tabular}{|r|c|c|c|c|}
\hline $\begin{array}{c}\mathrm{N}_{\mathrm{f}}, \\
\text { cycles }\end{array}$ & $\begin{array}{c}\text { Time to failure, } \\
\text { sec }\end{array}$ & $\begin{array}{c}\sigma_{\max }, \\
\mathrm{MPa}\end{array}$ & $\begin{array}{c}\sigma_{\min }, \\
\mathrm{MPa}\end{array}$ & $\begin{array}{c}\Delta \sigma, \\
\mathrm{MPa}\end{array}$ \\
\hline 555 & 10476 & 159.9 & 10.7 & 149.2 \\
1051 & 18432 & 156.6 & 10.3 & 146.3 \\
1227 & 22752 & 155.6 & 10.4 & 145.2 \\
939 & 18216 & 162.2 & 10.5 & 151.7 \\
\hline
\end{tabular}


TABLE III.-COMPARISON OF

PREDICTED FATIGUE LIVES

WITH EXPERIMENTAL RE-

SULTS (CYCLE FRE-

QUENCY $=0.05 \mathrm{~Hz}$ )

\begin{tabular}{|c|c|}
\hline $\begin{array}{c}\text { Measured life, } \\
\mathrm{N}_{\mathrm{f}}\end{array}$ & $\begin{array}{c}\text { Predicted } \\
\text { life, } \\
\mathrm{N}_{\mathrm{f}}\end{array}$ \\
\hline 555 & 693 \\
1051 & 1330 \\
1227 & 1242 \\
939 & 1135 \\
\hline
\end{tabular}

TABLE IV.-COMPARISON OF PREDICTED

FATIGUE LIVES WITH EXPERIMENTAL

RESULTS (CYCLE

FREQUENCY $=0.5 \mathrm{~Hz}$ )

\begin{tabular}{|c|c|c|c|}
\hline \multicolumn{2}{|c|}{ Experimental data } & \multicolumn{2}{|c|}{ Predicted results } \\
\hline $\begin{array}{c}\mathrm{N}_{\mathrm{f}}, \\
\text { cycles }\end{array}$ & $\begin{array}{c}\text { Time to } \\
\text { failure, } \\
\text { sec }\end{array}$ & $\begin{array}{c}\mathrm{N}_{\mathrm{f}}, \\
\text { cycles }\end{array}$ & $\begin{array}{c}\text { Time to } \\
\text { failure, } \\
\text { sec }\end{array}$ \\
\hline 20011 & 41868 & 18525 & $37080^{\mathrm{a}}$ \\
26323 & 45360 & 24862 & $49680^{\mathrm{b}}$ \\
\hline
\end{tabular}

${ }^{\mathrm{a}}$ Initial cavity radius $\left(\mathrm{a}_{0}\right)=0.35 \mu \mathrm{m}$.

${ }^{\mathrm{b}}$ Initial cavity radius $\left(\mathrm{a}_{0}\right)=0.41 \mu \mathrm{m}$. 


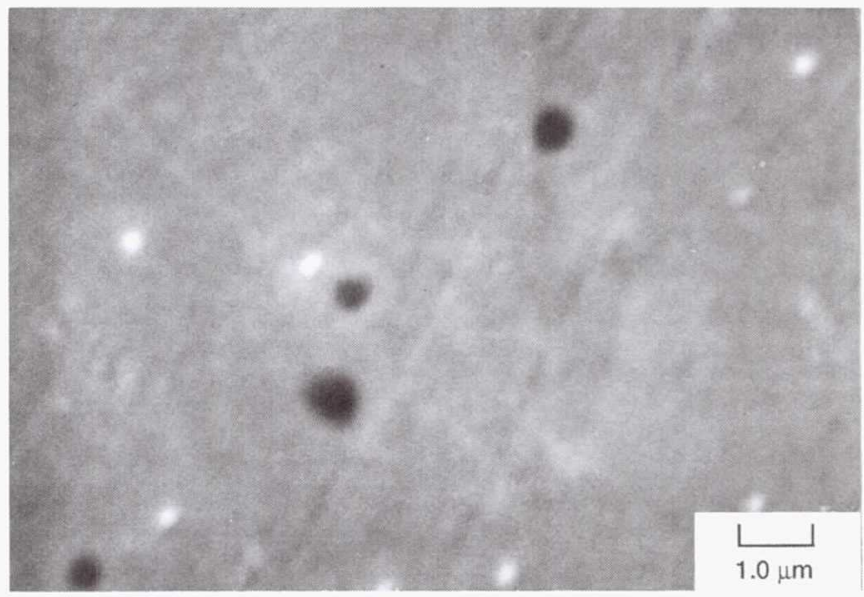

Figure 1.-SEM micrograph of the copper matrix of the as-received composite. Pre-existing cavities are shown along a grain boundary.

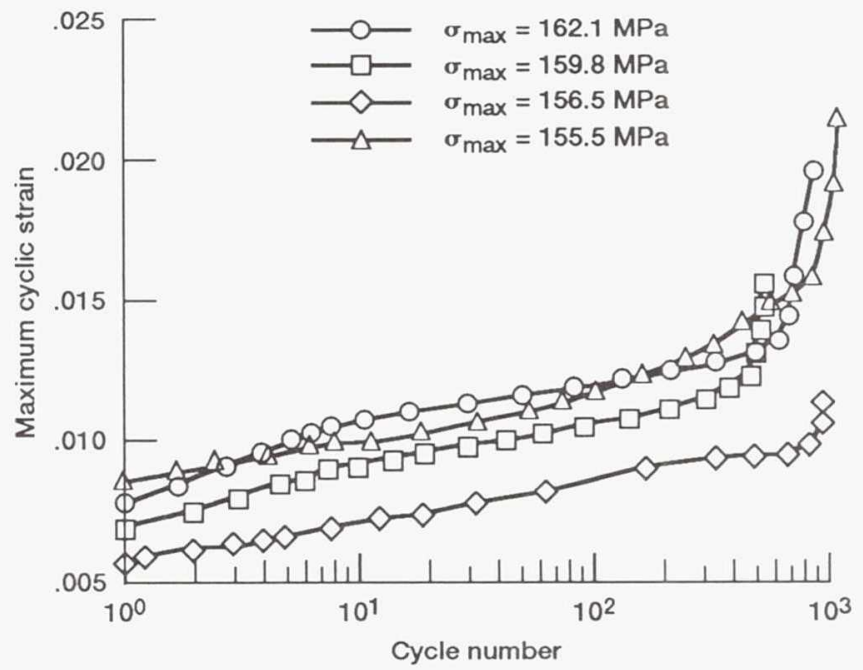

Figure 3.-Maximum cyclic strain versus cycle number for 9 vol. percent W/Cu fatigued at $833 \mathrm{~K}$.

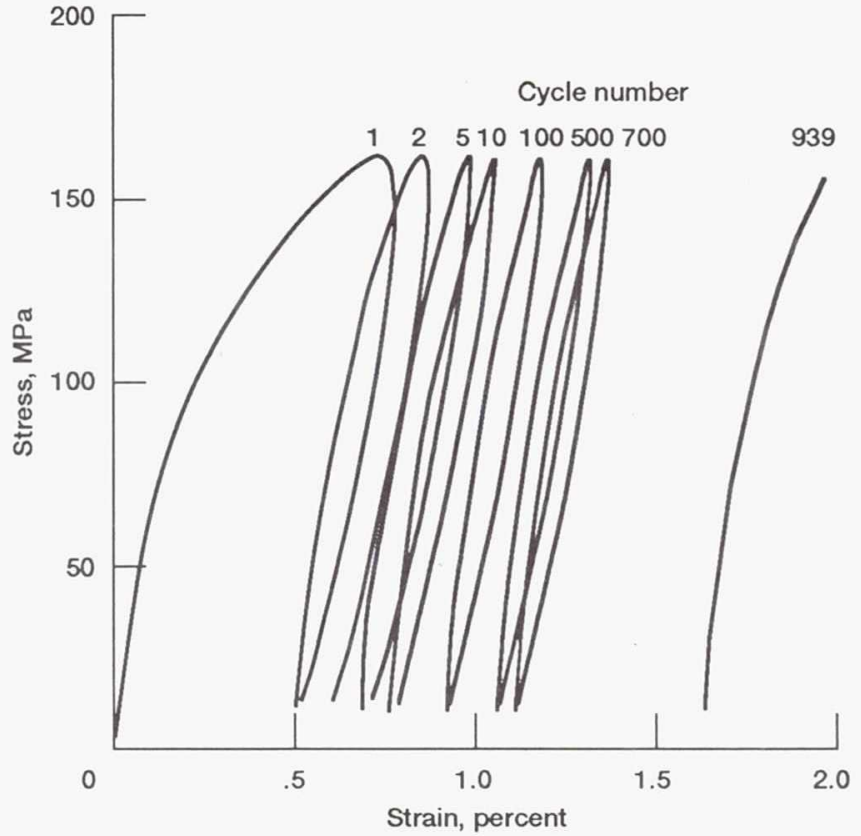

Figure 2.-Fatigue stress-strain response of the 9 vol. percent W/Cu composite tested at $833 \mathrm{~K} .\left(\Delta \sigma=152 \mathrm{MPa}, \mathrm{N}_{\mathrm{f}}=939\right)$

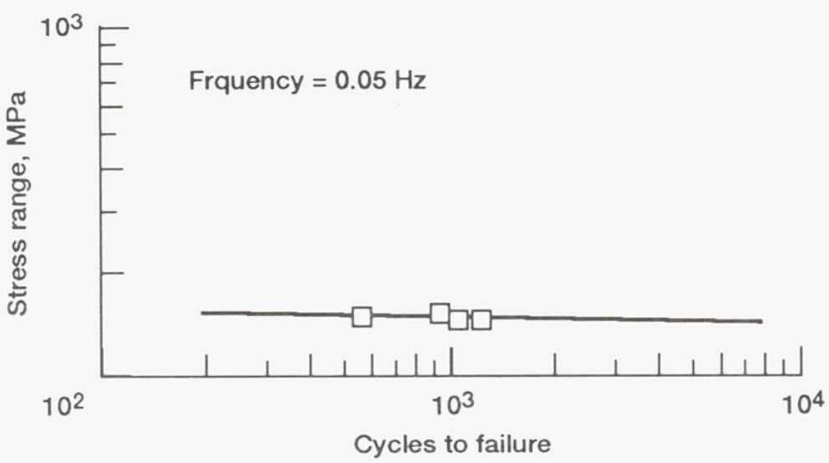

Figure 4.-Applied stress range as a function of fatigue life. Note the shallow slope of the S-N curve. 


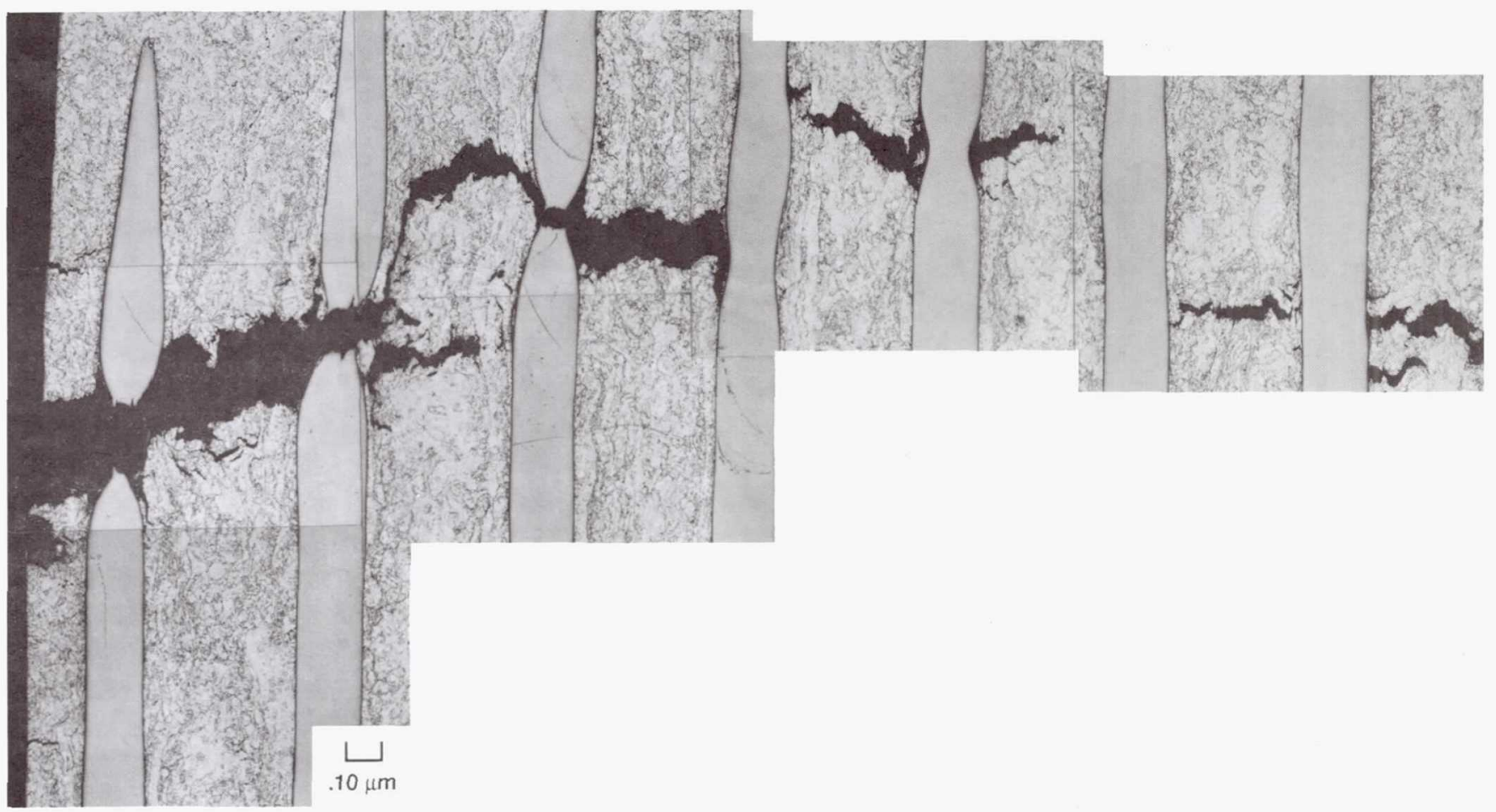

Figure 5.-Optical micrograph of polished longitudinal section of a specimen fatigued isothermally at $833 \mathrm{~K}$. Propagating crack from the specimen surface as well as cracks which were initiated inside the specimen are shown. Direction of loading is vertical. Arrow indicated direction of matrix cracking. Ductile failure of tungsten fibers is shown. 



Figure 6.-SEM micrograph of a failed composite specimen showing intergranular failure of the copper matrix.

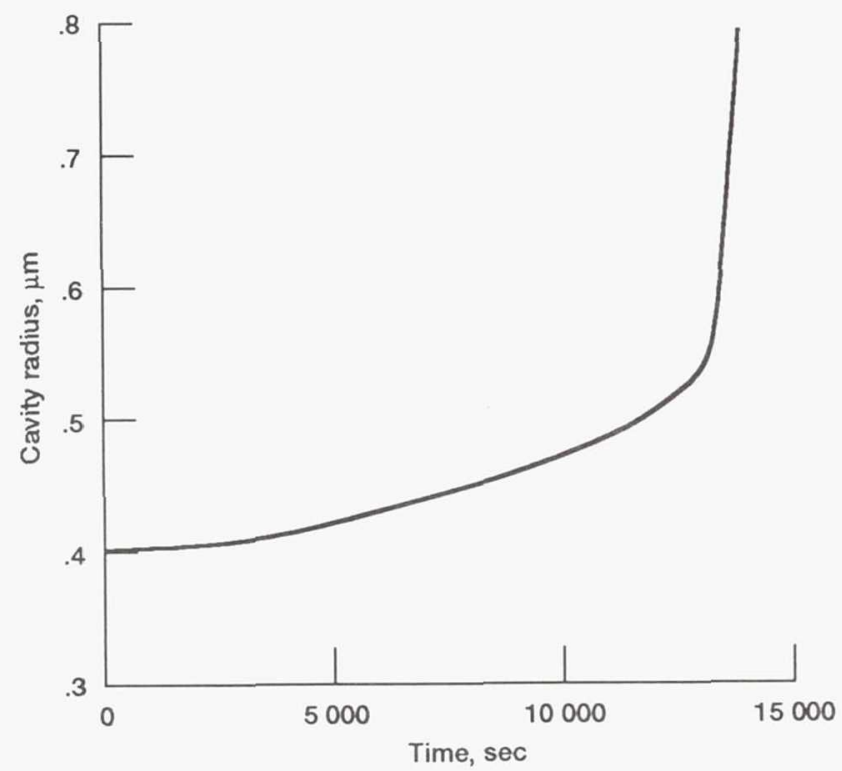

Figure 7.-Predicted cavity growth in the copper matrix as a function of time. The initial cavity radius was $0.4 \mu \mathrm{m}$. The simulation was for specimen of measured life $\mathrm{N}_{f}=$ cycles in Table 1. 


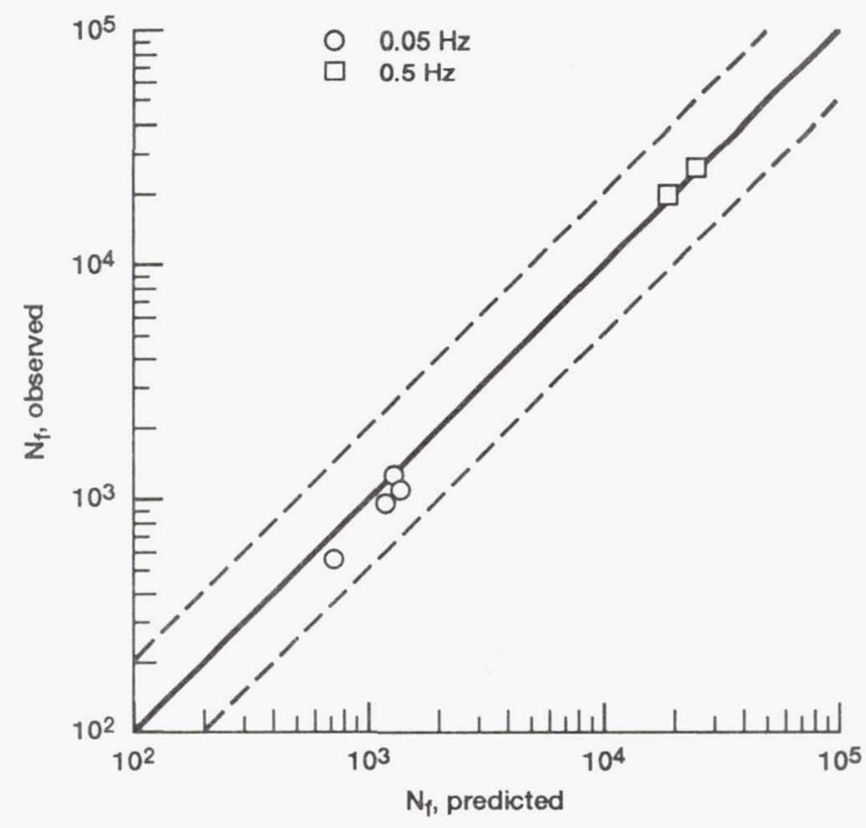

Figure 8.-Comparison of model-predicted results with experimental results. The solid line represents a perfect prediction, the dashed lines are deviation by factors of two. 




13. ABSTRACT (Maximum 200 words)

A microstructural model has been developed to predict creep-fatigue life in a $[0]_{4}, 9$ volume percent tungsten fiberreinforced copper matrix composite at the temperature of $833 \mathrm{~K}$. The mechanism of failure of the composite is assumed to be governed by the growth of quasi-equilibrium cavities in the copper matrix of the composite, based on the microscopically observed failure mechanisms. The methodology uses a cavity growth model developed for prediction of creep fracture. Instantaneous values of strain rate and stress in the copper matrix during fatigue cycles were calculated and incorporated in the model to predict cyclic life. The stress in the copper matrix was determined by use of a simple twobar model for the fiber and matrix during cyclic loading. The model successfully predicted the composite creep-fatigue life under tension-tension cyclic loading through the use of this instantaneous matrix stress level. Inclusion of additional mechanisms such as cavity nucleation, grain boundary sliding, and the effect of fibers on matrix-stress level would result in more generalized predictions of creep-fatigue life.

\section{SUBJECT TERMS}

Fatigue; Life prediction; Tungsten/copper; Metal matrix composite; High temperature cavitation

\section{SECURITY CLASSIFICATION OF REPORT}

Unclassified

18. SECURITY CLASSIFICATION
OF THIS PAGE
Unclassified

Unclassified
19. SECURITY CLASSIFICATION OF ABSTRACT

Unclassified
15. NUMBER OF PAGES 18

16. PRICE CODE $\mathrm{A} 03$

20. LIMITATION OF ABSTRACT 